\title{
Karakteristik Psikologis Siswa dalam Pembelajaran Matematika ditinjau dari Kecerdasan Intuitif dan Reflektif
}

\author{
Habibullah ${ }^{1}$, Gamarina Isti Ratnasari ${ }^{2}$, Puspitarani $^{3}$, Salviana $^{4}$ \\ ${ }^{1}$ Pendidikan Matematika, Universitas Islam Riau \\ ${ }^{2}$ Pendidikan Matematika, SMA Negeri 1 Bantul \\ ${ }^{3}$ Pendidikan Matematika, Universitas Negeri Yogyakarta \\ ${ }^{4}$ Pendidikan Matematika, SMP Negeri 42 Batam \\ *E-mail: habibullah_nz@yahoo.co.id
}

\begin{abstract}
ABSTRAK
Penelitian ini merupakan penelitian kualitatif deskriptif dengan menggunakan tinjauan literatur yang bertujuan untuk mendeskripsikan karakteristik psikologis siswa dalam pembelajaran matematika ditinjau dari kecerdasan intuitif dan reflektif.Kecerdasan intuitif adalah suatu istilah psikologi dalam proses pemahaman kognitif yang secara spontan memunculkan dan menyeleksi konsep ataupun skema yang sudah diketahuidengan cara memahami pengetahuan melalui sesuatu yang konkret, eksperimental, atau secara intelektual untuk merespon stimulus dengan tingkat akurasi yang tinggi. Sedangkan kecerdasan reflektif adalah proses kegiatan yang dilakukan dengan aktif, gigih, terarah dan penuh pertimbangan dalammenganalisis, mengevaluasi, memotivasi, mendapatkan makna yang mendalam, danmenggunakan strategi pembelajaran yang tepat. Kecerdasan intuitif dan reflektif memiliki peranan penting dalam pembelajaran di sekolah, sehingga sebaiknya perlu dikembangkan dalam proses pembelajaran khususnya pada pelajaran matematika agar dapat meningkatkan kemampuan siswa dalam memecahkan masalah.
\end{abstract}

Kata kunci: Karakteristik Psikologis Siswa, Kecerdasan Intuitif, Kecerdasan Reflektif

\section{Psychological Characteristics of Students in Mathematics Learning on Intuitive and Reflective Intelligence}

\begin{abstract}
This research is a descriptive qualitative research using literature review that aims to describe the psychological characteristics of students in learning mathematics on intuitive and reflective intelligence. Intuitive intelligence is a psychological term in the process of cognitive understanding that spontaneously raises and selects known concepts or schemes by understanding knowledge through something concrete, experimental, or intellectually to respond to a stimulus with a high degree of accuracy. While, reflective intelligence is a process of activities carried out actively, persistently, directed and thoughtfully in analyzing, evaluating, motivating, getting deep meaning, and using appropriate learning strategies. Intuitive and reflective intelligence has an important role in learning in school, so it should be developed in the learning process, especially in mathematics so that students can improve their ability to solve problems.
\end{abstract}

Keywords:Psychological Characteristics of Students, Intuitive Intelligence, Reflective Intelligence 


\section{PENDAHULUAN}

Matematika sering dianggap sebagai ilmu yang hanya menekankan pada kemampuan berfikir logis dengan penyelesaian yang tunggal dan pasti. Namun jika dilihat dari sudut pandang yang lain, matematika merupakan salah satu sarana berpikir ilmiah yang sangat berpengaruh dalam mengembangkan kemampuan berpikir kritis siswa. Pada dasarnya, siswa mempunyai bakat dan kemampuan yang berbeda di dalam setiap mata pelajaran, baik pada tingkat kecepatan, ketepatan maupun akurasi yang dibutuhkan di dalam menyelesaikan soal atau masalah yang diberikan oleh guru. Menurut Deporter \& Hernacki (1999) otak manusia memiliki wilayah-wilayah kecerdasan, ini berarti sepanjang anak manusia terlahir dengan memiliki otak, maka ia memiliki potensi untuk menjadi cerdas. Akan tetapi yang membuat setiap orang memiliki kemampuan yang berbeda adalah pemberian perlakuan atau stimulus positif pada masing-masing wilayah kecerdasan.

Padapembelajaran matematika kemampuan berpikir sangat diperlukan, sehingga siswa harus berpikir agar mampu memahami konsep-konsep matematika yang dipelajari serta mampu menggunakan konsep-konsep tersebut secara tepat ketika harus mencari solusi dari berbagai permasalahan matematika. Hal ini senada dengan pendapat Carson (2007) yang menyatakan bahwa kemampuan berpikir juga memiliki hubungan dengan kemampuan matematika siswa, seperti kemampuan pemecahan masalah dan prestasi belajar matematika siswa, karena dalam memecahkan masalah tentunya melibatkan proses berpikir untuk menyelesaikan masalah tersebut. Menurut Dewey, (1933) berpikir merupakan proses yang menghasilkan representasi mental yang baru melalui transformasi informasi yang melibatkan informasi yang kompleks antara berbagai proses mental, seperti penilaian, abstraksi, penalaran, imajinasi, dan pemecahan masalah. Dari pernyataan tersebut, guru dituntut agar dapat mengenal dan memahami berbagai macam karakteristik berfikir siswa, agar tujuan yang diharapkan dalam proses belajar mengajar dapat tercapai dengan optimal. Karakteristik tersebut diantaranya adalah kemampuan berfikir yang ditinjau dari kecerdasan intuitif dan kecerdasan reflektif. 


\section{METODE}

Penelitian ini merupakan penelitian kualitatif deskriptif dengan menggunakan tinjauan literatur yang bersifat sistematis dengan mengacu pada langkah-langkah berikut: (1) mengidentifikasi pertanyaan penelitian; (2) mengembangkan protokol penelitian; (3) menentukan lokasi dari sumber referensi (4) memilih sumber referensi yang sesuai dan berkualitas; (5) mensitesis sumber referensi; dan (6) mempresentasikan hasil penelitian.

\section{HASIL DAN PEMBAHASAN}

\subsection{Karakteristik Psikologis Siswa}

Menurut Uno (2012) karakteristik siswa adalah aspek-aspek atau kualitas seorang siswa yang terdiri dari minat, sikap, motivasi belajar, gaya belajar, kemampuan berpikir dan kemampuan awal yang dimiliki. Sementara itu, Sardiman (2001) menyatakan bahwa karakteristik siswa adalah keseluruhan pola kelakuan dan kemampuan yang ada pada siswa sebagai hasil dari pembawaan dan lingkungan sosialnya sehingga menentukan pola aktivitas dalam meraih cita-citanya. Dari pengertian tersebut memberikan gambaran bahwa tujuan pembelajaran adalah meningkatkan kompetensi anak, dan untuk keperluan tersebut seorang guru perlu mengetahui aspek-aspek perkembangan siswa. Seorang guru harus memahami karakteristik siswa, mengidentifikasi tingkat kemampuannya dan aspek-aspek perkembangannya.

Setiap siswa memiliki kemampuan dan kecerdasan yang berbeda-beda. Perbedaan inilah yang menuntut guru agar bersikaf adil dan arif dalam menyikapinya. Khodijah (2011) menyatakan bahwa perbedaan individual diantara peserta didik merupakan hal yang tidak mugkin dihindari, karena hampir tidak ada kesamaan yang dimiliki oleh manusia kecuali perbedaan itu sendiri. Sejauhmana individu berbeda akan mewujudkan kualitas perbedaan mereka atau kombinasikombinasi dari berbagai unsur perbedaan tersebut. Dengan perbedaan yang dimiliki siswa secara tidak langsung turut berperan aktif dalam membangun semangat dan rasa percaya diri siswa, baik secara fisiologis maupun psikologis. Karakteristik psikologis siswa tidak dapat dipisahkan dengan kepribadian. David dan Richard menyatakan bahwa kepribadian adalah integrasi dari semua karakteristik individu ke dalam suatu kesatuan yang unik yang menentukan, dan yang dimodifikasi oleh 
usaha-usahanya dalam menyesuaikan diri terhadap lingkungan yang berubah terusmenerus (Kuntjojo, 2009).

Alwisol (2005) menjelaskan bahwa ada lima konsep yang berhubungan erat dengan kepribadian diantaranya:

1. Character, yaitu penggambaran tingkah laku dengan menonjolkan nilai (banarsalah, baik-buruk) baik secara eksplisit maupun implisit.

2. Temperament, yaitu kepribadian yang berkaitan erat dengan determinan biologis atau fisiologis.

3. Traits, yaitu respon yang senada atau sama terhadap sekolompok stimuli yang mirip, berlangsung dalam kurun waktu (relatif) lama.

4. Typeattribute, mirip dengan sifat, namun dalam kelompok stimuli yang lebih terbatas.

5. Habit, merupakan respon yang sama dan cenderung berulang untuk stimulus yang sama pula.

Cara berfikir siswa di dalam kelas umumnya akan terlihat dari sikap mereka ketika menerima ilmu pengetahuan yang disampaikan oleh guru. Namun, pemikiran dan sikap tersebut masih tetap bisa dipengaruhi atau diarahkan guru kepada tujuan utama pelaksanaan pembelajaran. Karena temperamen berhubungan erat dengan keperibadian dan gaya berfikir, maka Santrock (2018) menyatakan bahwa ada tiga gaya dasar atau kelompok tempramen, yaitu:

1. Anak yang mudah (easy child), pada umumnya berada dalam suasana hati yang positif dengan cepat membentuk rutinitas tetap dimasa kecil dan dengan mudah beradaptasi dengan pengalaman baru.

2. Anak yang sulit (difficult child), bereaksi secara negatif dan sering menangis, terlibat dalam rutinitas harian yang tidak tetap, serta pelan menerima perubahan.

3. Anak yang lambat (slow-to-warm-up child), mempunyai tingkat aktifitas yang rendah, agak negatif dan menunjukkan intensitas suasana hati yang rendah.

Dalam pendidikan yang melibatkan tempramen siswa, para guru bisa memperhatikan dan menghormati individualitas, pertimbangkanlah struktur lingkungan seorang siswa, sadarilah masalah yang terlibat ketika menjuluki seorang siswa "sulit", menggunakan strategi kelas yang efektif untuk anak-anak yang sulit, malu, lambat, dan anak-anak yang kesulitan mengatur emosi mereka. 


\subsection{Kecerdasan Intuitif}

Menurut Fischbein (2002) kecerdasan intuitif adalah proses kognitif yang spontan dan segera berdasarkan pada skema tertentu. Sementara itu, Perkin menyatakan bahwa kecerdasan intuitif merupakan kemampuan untuk memunculkan dan menyeleksi konsep atau skema yang sudah diketahui untuk merespon stimulus secara otomatis dan spontan dengan tingkat akurasi yang tinggi. Kecerdasan ini mencerminkan peranan pengetahuan dalam membantu kita untuk memutuskan dan bertindak lebih efektif (Warti, 2013). Sedangkan, menurut Plato dan Aristoteles intuitif merupakan proses berpikir yang serupa dengan proses berpikir Tuhan. Intuitif dicirikan sebagai hasil berpikir yang: (1) tidak temporal yaitu memiliki keputusan yang sulit berubah; (2) memandang keseluruhan objek daripada bagian-bagian objek; (3) tidak bersifat proposisional; (4) tidak bersifat representasional; dan (5) karena ia dipandang serupa dengan proses berpikir Tuhan maka intuitif dianggap tidak pernah salah (Henden, 2004).

Dreyfus \& Eisenberg (1982) menyatakan bahwa pemahaman secara intuitif sangat diperlukan sebagai "jembatan berpikir" manakala seseorang berupaya untuk menyelesaikan masalah dan memandu menyelaraskan kondisi awal dengan tujuan. Dengan kata lain, untuk beberapa siswa pada saat menyelesaikan masalah matematika telah mengetahui atau menemukan solusi/jawaban dari suatu masalah sebelum siswa menuliskan langkah penyelesaiannya. Meskipun, pada saat mereka menemukan ide awal dalam penyelesaian masalah atau langkah apa yang paling cocok untuk menyelesaikan masalah tersebut. Munculnya ide yang datang secara seketika dan bersifat otomatis atau muncul tiba-tibamerupakan karakter berpikir yang melibatkan intuitif (Sa'o, 2016).

Menurut Skemp (1971) pada tingkat intuitif, kita mengetahui akan data-data dari lingkungan luar melalui alat-alat penerima kita (terutama penglihatan dan pendengaran). Hal ini dikarenakan, secara otomatis data tersebut diklasifikasikan dan dihubungkan dengan data serupa yang sudah ada. Dengan otot-otot yang dimiliki, kita dapat menggerakan kerangka untuk berbuat pada lingkungan luar (Suatu uraian yang meliputi bicara dan menulis). Aktifitas ini banyak dikontrol dan diarahkan oleh umpan balik, selanjutnya informasi mengenai kemajuan dan hasilnya dapat diketahui melalui reseptor luar. Dalam banyak kasus, hal tersebut dapat berhasil tanpa adanya kesadaran. Misalnya, ketika membaca dengan suara keras, 
mengemudikan mobil, atau menjawab pertanyaan $16 \times 25$. Berikut skema tentang kecerdasan intuitif.

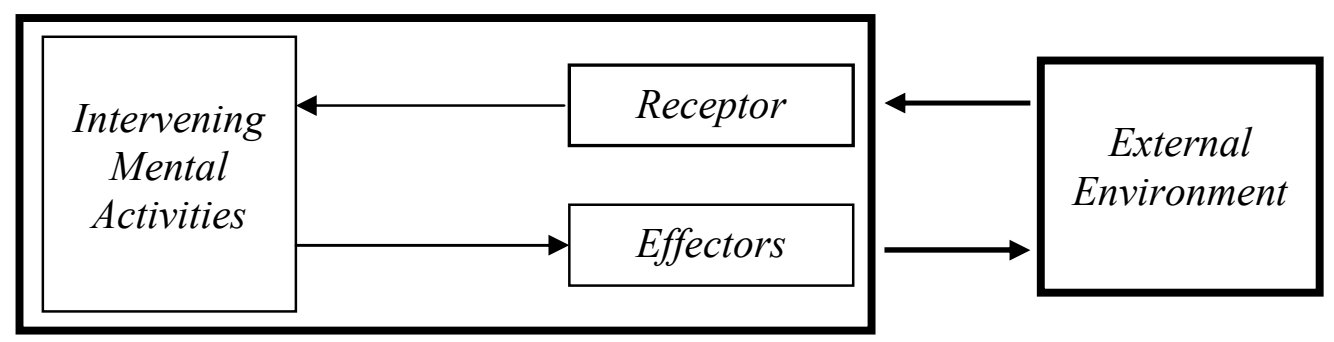

\section{Gambar 1. Skema Kecerdasan Intuitif}

Baylor (2001) menyatakan bahwa perkembangan intuitif seseorang dipengaruhi oleh tingkat kepakarannya dibidang tertentu. Secara kualitatif terdapat dua jenis intuitif, yaitu intuitif yang yang belum matang (Immature intuition) dan intuitif yang sudah matang (mature intuition). Intuitif yang belum matang sering dijumpai ketika seseorang masih berada pada taraf pemula dibidang tertentu, dimana pengetahuan analitiknya belum banyak mencampuri kemampuannya dalam menemukan wawasan-wawasan baru. Sedangkan intuitif yang sudah matang kebanyakan muncul ketika seseorang sudah mencapai kepakaran di bidang tertentu dengan modal struktur pengetahuan relevan yang sudah terbentuk dengan baik. Menurut Skemp (1971) siswa yang masih pada tahap intuitif, biasanya banyak tergantung pada cara penyajian materi oleh guru. Jika konsep baru yang didapati sangat jauh dari skema yang ada, mungkin dia tidak mampu mengasimilasikannya, khususnya karena tingkat akomodasi yang mungkin pada tingkat intuitif lebih rendah daripada yang dicapai dengan refleksi. Maka pada tahap-tahap awal, guru harus menganalisis konseptual siswa secara cermat sebagai dasar merencanakan pembelajaran, sehingga siswa dapat melakukan sintesa struktur-struktur dalam ingatannya sendiri. Itulah hal yang harus diperhatikan, tidak peduli apakah pembelajaran terjadi langsung oleh guru, maupun pembelajaran tidak langsung yaitu dari buku. Pendekatan ini lebih fleksibel, disesuaikan dengan penguasaaan siswa sehingga tidak harus tepat sesuai rencana yang telah disiapkan.

\subsection{Kecerdasan Reflektif}

Bergson (Henden, 2004) menyatakan bahwa berpikir memiliki dua sisi yang berlawanan arah. Jika berpikir bersifat discursive dan analytic quantitative perspective, maka jenis berpikir ini disebut intelek. Tetapi jika berpikir bersifat non- 
discursive atau qualitative perspective, maka jenis berpikir ini disebut intuitif. Karena intuitif bersifat non-discursive maka penalaran tidak memainkan perananan dalam intuitif. Penalaran menghasilkan kesimpulan dari pikiran, kejelasan, dan ketegasan dan melibatkan penyelesaian masalah untuk menjelaskan mengapa sesuatu terjadi atau apa yang akan terjadi (Schunk, 2012).

Dewey (1933) mendefinisikan berfikir reflektif sebagai sesuatu yang dilakukan dengan aktif, gigih, dan penuh pertimbangan keyakinan didukung oleh alasan yang jelas dan dapat membuat kesimpulan/memutuskan sebuah solusi untuk masalah yang diberikan. Sedangkan, Gurol (2011) mendefinisikan berpikir reflektif sebagai proses kegiatan terarah dan tepat dimana individu menganalisis, mengevaluasi, memotivasi, mendapatkan makna yang mendalam, menggunakan strategi pembelajaran yang tepat.

Skemp (1971) mengatakan pada tahap reflektif, aktifitas mental yang telah berintervensi menjadi obyek kesadaran untuk introspeksi diri. Sebagai contoh seorang siswa yang menumpang kendaraan bertanya? "mengapa memindahkan versnelling sebelum mencapai belokan tajam di jalan. Biarpun kita telah berbuat begitu 'tanpa berfikir', kita tidak kesulitan untuk menjelaskan alasan tersebut". Berikut merupakan skema kecerdasan reflektif.

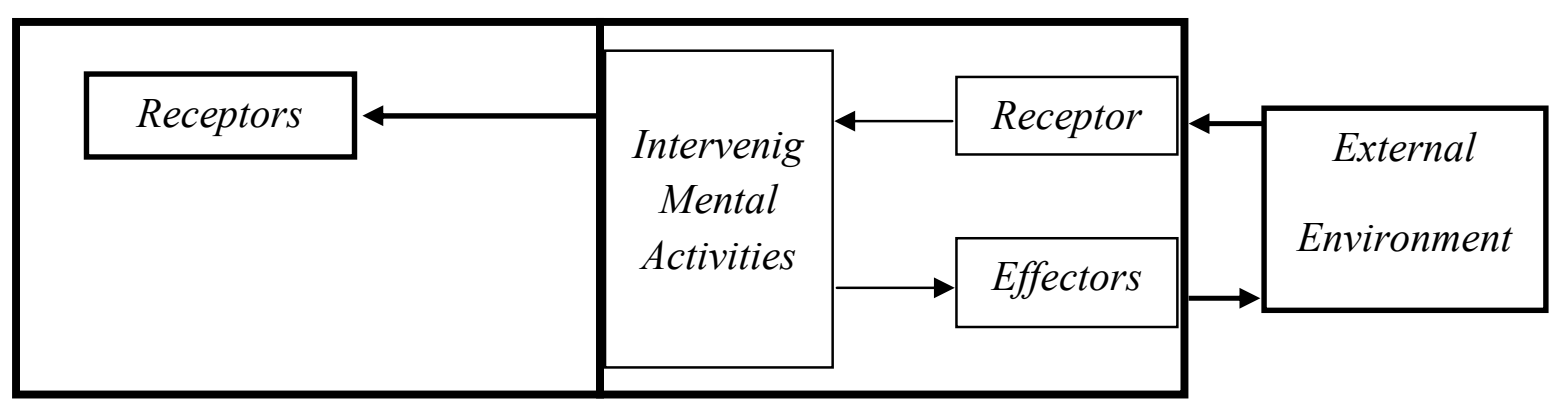

\section{Gambar 2. Skema Kecerdasan Reflektif}

Berpikir reflektif memberikan kesempatan bagi siswa untuk memecahkan masalah dengan disertai alasan yang logis, mempertahankan pendapat mereka, menganalisis dan berpikir kembali ketika merespon atau memilih solusi yang berguna dalam memecahkan masalah (Kurniawati, 2011). Hal ini sejalan dengan pernyataan King \& Kitchener (Griffith \& Frieden, 2000)yang mengatakan bahwa berpikir reflektif melibatkan identifikasi fakta, formula, dan teori yang relevan untuk memecahkan masalah yang kompleks dan tidak jelas. Rudd menyatakan peran penting dari berpikir reflektif adalah sebagai sarana untuk mendorong pemikir 
selama situasi pemecahan masalah karena memberikan kesempatan untuk melangkah mundur dan memikirkan strategi terbaik untuk mencapai tujuan (Choy \& Oo, 2012). Sebagaimana yang dinyatakan oleh Gurol (2011) bahwa faktor paling penting yang memisahkan pemikiran reflektif dari semua jenis berpikir adalah bahwa berpikir reflektif muncul sebagai solusi menafsirkan, menunda, menerjemahkan, mendapatkan dan memahami isu-isu berpikir dalam prediksi dan pengambilan keputusan untuk masa depan.

\subsection{Proses Berfikir Matematika Berdasarkan Kecerdasan Intuitif dan Reflektif}

Skemp (1971) menyatakan bahwa suatu jenis kegiatan reflektif yang jangkauannya lebih jauh adalah aktivitas yang mengarah pada generalisasi matematis. Secara jelas dapat dibedakan dalam dua tahap melalui contohsebagai berikut.

$a^{2}=a \times a$

$a^{3}=a \times a \times a$

$a^{4}=a x \quad a \times x \quad a \times a$, dan seterusnya.

Dengan mudah dapat dilihat bahwa:

$$
\begin{aligned}
a^{2} x a^{3} & =a \times a \quad x \quad \text { axaxa } \\
& =a^{5}
\end{aligned}
$$

Dari sini dengan contoh-contoh yang sama, siswa secara intuitif dapat membentuk skema umum sehingga dapat segera menulis:

$a^{5} x a^{7}=a^{12}, \quad$ dan seterusnya.

Dengan menggunakan cara-cara manipulasi pecahan-pecahan aljabar yang sudah diktahui, siswa juga dapat membentuk skema untuk pembagian, seperti contoh berikut;

$a^{5} \div a^{2}=\frac{a \times a \times a \times a \times a}{a \times a}=a \times a \times a=a^{3}$, Sehingga siswa dapat segera menulis:

$a^{15} \div a^{6}=a^{9}$, dan seterusnya.

Sesudah membentuk dua skema yang bertalian ini, siswa juga dapat merumuskannya yaitu dengan menyatakan secara simbolik yang membentuk:

$\left[a^{\mathrm{m}} x a^{\mathrm{n}}=a^{\mathrm{m}+\mathrm{n}}\right]$ dan $\left[a^{\mathrm{m}} \div a^{\mathrm{n}}=a^{\mathrm{m}-\mathrm{n}}\right]$

Untuk $m$ dan $n$ mewakili dua bilangan cacah selain nol, dan dikasus kedua $m>n$. Sehingga aturan tersebut hanya berlalu untuk $a, a^{2}, a^{3}, \ldots$ dan tidak berlaku 
untuk $a^{0}, a^{-2}, a^{1 / 2}$, sehingga batasan $m$ dan $n$ adalah bilangan asli harus dihilangkan. $a^{0}$ diberi arti $1, a^{-2}$ diberi arti $1 / a^{2}$, dan $a^{1 / 2}$ diberi arti $\sqrt{a}$.

Proses generalisasi matematika yang telah diuraikan tersebut, adalah suatu aktivitas yang kuat dan canggih. Canggih, karena melibatkan refleksi dalam bentuk metoda, sementara mengabaikan isinya. Kuat, karena membuat kemungkinan yang terkendali, terkontrol, dan akomodasi yang akurat dari skema yang telah ada, tidak hanya sebagai jawaban atas permintaan untuk asimilasi dari situasi baru sebagaimana mereka temukan, tetapi garis besar pernyataan ini, mencari atau menciptakan yang baru untuk kecocokan perluasan konsep. Penggunaan kemampuan intuitif sebenarnya hanya permasalahan datang dan pergi yang sifatnya sementara dan tidak berupa susunan-susunan yang teratur(Skemp, 1971).

Berdasarkan penjelasan di atas, memberikan fakta terkait dengan berpikir intuitif dan berpikir reflektif.Hal ini menjadi bukti bahwa kedua kemampuan berpikir ini memberikan peran penting dalam pembelajaran matematika di sekolah, sehingga berpikir intuitif dan berpikir reflektif banyak dikembangkan dalam pembelajaran matematika agar dapat meningkatkan kemampuan siswa dalam memecahkan masalah.

\section{KESIMPULAN}

Matematika bukanlah ilmu hitung semata, tetapi juga merupakan ilmu yang membutuhkan kemampuan untuk berpikir dan bernalar secara logis dan kritis. Karena setiap siswa memiliki kecerdasan matematika yang berbeda, sehingga guru matematika mempunyai tugas ganda yaitu selain harus menguasai materi pelajaran matematika dengan baik, juga harus menguasai cara menyajikan materi pelajaran agar dapat mengembangkan kemampuan skema berpikir matematika siswa yang meliputi kecerdasan intuitif dan reflektif.Kecerdasan intuitif adalah suatu istilah psikologi dalam proses pemahaman kognitif yang secara spontan memunculkan dan menyeleksi konsep ataupun skema yang sudah diketahui dengan cara memahami pengetahuan melalui sesuatu yang konkret, eksperimental, atau secara intelektual untuk merespon stimulus dengan tingkat akurasi yang tinggi. Sedangkan kecerdasan reflektif adalah proses kegiatan yang dilakukan dengan aktif, gigih, terarah dan penuh pertimbangan dalam menganalisis, mengevaluasi, memotivasi, mendapatkan makna yang mendalam, dan menggunakan strategi pembelajaran 
yang tepat.Dengan demikan, dalam proses pembelajaran guru harus mengurangi ketergantungan siswa terhadap dirinya dan memberi kebebasan kepada siswa untuk dapat mengembangkan ide-ide kreatif mereka dalam proses belajar khususnya pada pelajaran matematika.

\section{DAFTAR PUSTAKA}

Alwisol. (2005). Psikologi kepribadian. Malang: Universitas Muhammadyah Malang.

Baylor, A. L. (2001). A U-shaped model for the development of intuition by level of expertise. New Ideas in Psychology, 19, 237-244.

Carson, J. (2007). A Problem with problem solving: Teaching thinking without teaching knowledge. The Mathematics Educator, 17(2), 7-14.

Choy, S. C., \& Oo, P. S. (2012). Reflective thinking and teaching practices: A precursor for incorporating critical thinking thto the classroom? International Journal of Instruction, 5(1), 167-182.

Deporter, B., \& Hernacki, M. (1999). Quantum learning: Membiasakan belajar nyaman dan menyenangkan. Bandung: Kaifa.

Dewey, J. (1933). How we think: A restatement of the relation of reflective thinking to the educative process. Boston: D.C. Heath \& Co Publishers.

Dreyfus, T., \& Eisenberg, T. (1982). Intuitive functional concepts: A baseline study on intuitions. Journal for Research in Mathematics Education, 13(5), 360-380.

Fischbein, E. (2002). Intuition in science and mathematics: An educational approach. New York: Kluwer Academic Publishers.

Griffith, B. A., \& Frieden, G. (2000). Facilitating reflective thinking in counselor education. Counselor Education and Supervision, 40(2), 82-93.

Gurol, A. (2011). Determining the reflective thinking skills of pre-service teachers in learning and teaching process. Energy Education Science and Technology Part B: Social and Educational Studies, 3(3), 387-402.

Henden, G. (2004). Intuition and its role in strategic thinking. Sandvika: BI Norwegian School of Management.

Khodijah, N. (2011). Psikologi pendidikan. Palembang: Grafika Telindo Press.

Kuntjojo. (2009). Psikologi kepribadian. Kediri: Universitas Nusantara PGRI Kediri.

Kurniawati, L. (2011). Developing mathematical reflektive thinking skills through problem based learning. In Proceeding International Seminar and the Fourth National Conference on Mathematics Education. Universitas PGRI Yogyakarta.

Sa'o, S. (2016). Berpikir intuitif sebagai solusi mengatasi rendahnya prestasi belajar matematika. Jurnal Review Pembelajaran Matematika, 1(1), 43-56. https://doi.org/10.15642/jrpm.2016.1.1.43-56 
Santrock, J. W. (2018). Educational psychology (6th ed.). New York: McGraw-Hill Education.

Schunk, D. H. (2012). Learning theories an educational perspective (8th ed.). Boston: Allyn \& Bacon.

Skemp, R. R. (1971). The psychology of learning mathematics. England: Penguin Books.

Uno, H. B. (2012). Orientasi baru dalam psikologi pembelajaran. Jakarta: Bumi aksara.

Warti, R. (2013). Kecerdasan intuitif dan kecerdasan reflektif. Edu-Math, 4. 